Secondary publication on the edoc server of the Humboldt-Universität zu Berlin https://doi.org/10.18452/21583

This is an Accepted Manuscript of an article published by Taylor \& Francis in International Journal of River Basin Management on 23/08/2010, available online: http://www.tandfonline.com/ 10.1080/15715124.2007.9635312

Originally published as:

Timothy Moss (2007) Institutional drivers and constraints of floodplain restoration in Europe, International Journal of River Basin Management, 5:2, 121-130, DOI:

$\underline{10.1080 / 15715124.2007 .9635312}$

\title{
Institutional drivers and constraints of floodplain restoration in Europe
}

\author{
Timothy Moss
}

\begin{abstract}
The task of restoring floodplains, as a means of improving flood protection or providing other benefits, poses multi-dimensional challenges to policy-makers and project managers alike. Involving essentially a reconfiguration of the interaction between a river and adjacent lowlying land, floodplain restoration affects a wide range of institutions designed to secure a variety of private and public goods associated with water and land use. A scheme to restore a floodplain requires the successful enrolment of these institutions in such a way as to create a result acceptable to the principal stakeholders. This is a highly complex process. This paper, based on EU-funded research on the policy contexts and selected pilot schemes of floodplain restoration in Germany, France and England and Wales, provides a critical appraisal of the institutional drivers and constraints of floodplain restoration. In particular, it explores how recent shifts in problem awareness and problem-solving in a number of relevant policy fields are creating windows of opportunity for more integrated approaches to restoring floodplains. At the same time it demonstrates the emergence of a new policy delivery gap emanating from the growing complexity of new generation floodplain restoration schemes. Keywords: floodplain restoration, institutions, river basin management, policy implementation
\end{abstract}




\section{Introduction}

Despite the considerable advancement of scientific knowledge on the functioning of floodplain ecosystems and the regulation of rivers (e.g. Petts 1996; Brookes 1996; Ward et al. 1999; Hughes and Rood 2001; Hughes 2003) there exist in Europe as yet very few instances where this knowledge has been translated into an operational scheme to restore functional floodplains. Floodplain restoration we understand to mean the creation of ecosystems typical of floodplains on low-lying land which exhibit a hydrological link between river and land. Whereas river restoration has in recent years become a widely practised form of environmental enhancement in Western Europe, floodplain restoration is under-developed, being limited largely to a few, small-scale demonstration sites. Why is this the case when floodplains represent some of the most species-rich and endangered ecosystems in Europe?

Beyond the immediate difficulties of designing the hydrological and geomorphological attributes of a functional floodplain the task of restoring floodplains is fraught with institutional complexities, uncertainties and conflicts. Floodplains are interfaces not only between water and land, but also between a plethora of interests associated with the use of a

river and its adjacent land. These can range from providing protection from flooding, enabling development on prime locations and maximising agricultural production to improving the landscape value, recreational facilities and biodiversity of a floodplain. The task of restoring floodplains is particularly complex because it entails substantial changes to established practices of land and river management and, consequently, requires the support of multiple institutions each designed to pursue particular objectives.

Surprisingly little is known about the institutional dimensions of floodplain restoration. Most studies of individual schemes focus on the physical/technical features, treating socioeconomic issues, if at all, only with regard to cost-benefit assessments. There exists as yet no systematic analysis of the policy contexts of floodplain restoration in individual European countries. This paper is designed as an initial step towards filling this knowledge gap, providing a critical appraisal of the institutional drivers and constraints of floodplain restoration. It assesses why it has been so difficult to restore functional floodplains in the past. It explores how recent shifts in problem awareness and problem-solving in a number of relevant policy fields are creating windows of opportunity for more integrated approaches to restoring floodplains, giving rise to a number of large-scale, multi-purpose schemes. It 
reveals, though, how the growing complexity of new generation restoration schemes and the constraints posed by new policy procedures are hampering implementation and creating a new policy delivery gap. In this way the paper questions some of the high expectations attached to the new policy initiatives and restoration schemes alike and takes issue with some current practices of policy implementation and project management. It draws on concepts of fit, interplay and scale from the international literature on environmental institutions to help interpret the principal challenges and responses to floodplain restoration.

The research for this paper was conducted in the context of an interdisciplinary research project on floodplain biodiversity and restoration - FLOBAR 2 - funded by the European Commission within the Fifth Framework Programme and coordinated by the University of Cambridge. The work on institutional aspects was designed to set micro-analyses of individual floodplain restoration schemes in a broader context of the institutional framework and dynamics of water management at national, regional and local levels in three Member States. As the first step in this funnelled research strategy, an analysis was conducted of the formal institutions pertinent to river basin management in France, Germany and England and Wales. The second step was to investigate the institutional mechanisms affecting the restoration of floodplains in these countries. Policy analyses in each country, based on document analysis and face-to-face interviews, identified the principal policy, legislative and planning instruments relevant to floodplain restoration and assessed how they work in practice. The third step was to conduct case studies of two schemes of floodplain restoration in each of the three countries, again with interviews and document analysis. The selection of case studies was informed by the desire to include on the one hand schemes which were already completed, in order to observe their evolution and assess their impact, and on the other hand more recent schemes which reflect the shift towards a more integrated, catchmentoriented approach to floodplain restoration.

\section{Interconnectivity and boundary crossing: institutional complexities of restoring floodplains}

The task of restoring floodplains poses multi-dimensional challenges to policy-makers and project managers alike. Involving essentially a reconfiguration of the interaction between a river and adjacent low-lying land, floodplain restoration has far-reaching implications for 
existing forms of water and land use. Floodplains provide multiple functions and services for humans as well as the natural environment. These can range from valuable artefacts for socioeconomic reproduction, such as crops, timber, water or prime land for development to less tangible but equally valuable functions, such as protection from flooding, attractive landscapes or opportunities for recreational pursuits. The restoration of functional floodplains requires changes to existing activities on the site of the floodplain itself but also - particularly in the case of larger schemes - along whole reaches of a river and even a whole catchment. Maintaining desirable river flow dynamics demands a catchment perspective to river regulation and cooperation between upstream and downstream users. On this wider scale floodplain restoration can significantly influence, for instance, levels of flood protection, the navigability of a river reach or the viability of current farming practices. In this way floodplain restoration affects a wide range of stakeholders and interests (Adams and Perrow 1999:94-95; Adams et al. 2004; Turner et al. 2000:13-14; Adger and Luttrell 2000:78), making it potentially highly controversial. Striking an optimal balance between the multiple services a floodplain can provide, to humans and the wider natural environment, requires agreement between many actor groups spanning a variety of policy fields.

Behind these stakeholders and interests lie institutions, understood here as rule systems, designed to protect and provide a variety of private and public goods, ranging from commercial products to rights of access. For each of the policy fields affected by floodplain restoration - primarily water protection, flood defence, nature conservation, recreation, navigation, agriculture, urban and rural development - complex institutional arrangements have been designed and adapted over the years. Each institutional arrangement comprises a set of codified norms (such as laws, regulations and contractual obligations), planning instruments and funding mechanisms, as well as standardised procedures of operation, values and accepted practices of the relevant organised and individual actors. These institutions span a wide range of often diverse interests and pursue often competing objectives. A scheme to restore a floodplain requires the successful enrolment of these institutions and organisations in such a way as to create a result acceptable to the principal stakeholders. This is a highly complex process.

Managing the interdependence of multiple functions, actors and institutions is, however, not the only major socio-political challenge of floodplain restoration. Considerable uncertainty is generated by the diverse spatial scales and time frames involved. Restoring a floodplain 
requires consideration of the longitudinal connectivity of a floodplain to river uses both upand downstream as well as of the lateral connectivity to ways in which adjacent land is used (Adams and Perrow 1999). Even on site, interventions generally cut across several functional and administrative boundaries. These can relate to the spatial remit of local landowners and farmers, planning authorities, government agencies, protected areas or infrastructure networks (e.g. railways, roads, canals). Temporally, functional floodplains are characterised by their dependence on flooding events, which are by their nature periodic and unpredictable, and by significant time lags between changes in biotic and abiotic systems (Adams and Perrow 1999:93). Socio-economically, too, the process of restoring a floodplain is framed by diverse time scales, ranging from the payback periods for investments in altered practices of agriculture and forestry to the electoral periods of key public authorities. Floodplain restoration is, therefore, not only highly complex but also highly unpredictable. The institutional challenge is further complicated by the fact that many institutional arrangements, in particular for nature conservation, exhibit a strong tendency to protect existing conditions rather than encourage change and those which do pursue change are generally geared towards achieving specific targets rather than creating suitable frameworks for open-ended processes, as is required for functional floodplains.

\section{Effective institutions: the search for optimal fit, interplay and scale}

Our knowledge of institutions which can support - or obstruct - the protection of public goods such as water, flood defence and biodiversity has been developing rapidly over the past decade (cf. Breit et al. 2003). We know, however, relatively little about the institutional dimensions of floodplain restoration itself. Exceptions include studies of institutional constraints and complexities (Adams and Perrow, 1999; Hodge and McNally 2000), competing discourses of floodplain restoration (Adams et al. 2004), relevant EU policies (WWF, 2000, 2004) and European case studies (e.g. Zöckler 2000; Tunstall et al. 1999) as well as economic valuations of the functions and services provided by floodplains or wetlands (Gren et al. 1995; Turner et al. 2000; Adger and Luttrell 2000).

The Science Plan of the Institutional Dimensions of Global Environmental Change Project (IDGEC) of the International Human Dimensions Programme (IHDP) offers useful analytical frameworks for conceptualising some of the essential institutional challenges of resource 
management in general and floodplain restoration in particular (Young 1999; 2002). It identifies three generic factors influencing the effectiveness of environmental institutions: problems of fit, problems of interplay and problems of scale.

The issue of fit addresses the need to develop institutional arrangements which match the properties of the biogeophysical systems they are designed to regulate. Fit can relate to a variety of ecosystem properties. The following are identified in the IDGEC Science Plan: closed vs. open systems; heterogeneity/homogeneity; interdependencies among subsystems; simplicity/complexity; productivity/metabolism; cyclicity/periodicity; resilience; equilibria; dynamics (Young 1999:47). Problems of spatial misfit are a particularly common cause of institutional ineffectiveness. The territories covered by institutions rarely match those of biogeophysical systems, resulting in an inability of the institutions to internalise external effects (both positive and negative) effectively. The management of floodplains is fraught with boundary problems of this kind. Floodplain restoration not only works across a variety of physical spaces along the river and across the catchment, but also involves institutions and organisations from multiple policy fields - from nature conservation and flood defence to agriculture - each with their own spatial remits and territories of action.

Interplay relates, by contrast, to interdependencies between different institutions. The assumption here is that the effectiveness of an institution depends not solely on its inherent qualities but also on good embeddedness in existing institutional contexts. Institutional interplay can be horizontal, between different policy fields, and vertical, between different levels of social organisation. A further distinction is made between functional linkages emanating from the properties of the institutions involved and political linkages as expressions of deliberation (Young 2002). Problems of interplay are very familiar to efforts to restore floodplains, which are often confounded by the inability to bridge differences in the objectives, power structures and modes of action of the various key organisations. Horizontal interplay is complicated by the number of policy fields affected and vertical interplay by the increasing role of the EU and catchment-scale approaches to floodplain management.

Problems of scale can be of a spatial and a temporal nature. Spatially, the effectiveness of an institution depends on finding the appropriate level of social organisation for specific instruments and measures, taking consideration of the connectivity between scales and the needs this creates for multi-level and multi-directional forms of governance. Temporally, the 
issue of scale is about managing the diverse time-frames within which actors operate, policies are designed, projects are implemented, ideas are generated etc.. Here, too, the relevance to floodplain restoration is self-evident. Identifying the appropriate spatial scale for policy development, strategic guidance, operational management, public participation etc. is of paramount importance. Similarly, actors operate according to very different time-scales, some of which are rigid and predictable, others much less so.

Previous research on problems of fit, interplay and scale suggests that solutions are rarely straightforward. For instance, efforts to overcome problems of spatial fit by institutionalising river basin management can create new misfits and disturb existing modes of interplay (Moss 2003). Success would appear to be dependent not on attempting to reduce the given complexities in search of the perfect fit or scale but on finding ways of accommodating complexity. Given that substantial uncertainties will continue to surround floodplain restoration despite advances in our knowledge of the physical, biological and socio-political systems, it makes sense to seek coping strategies suited to specific contexts rather than a universally applicable blueprint. Before investigating the diverse strategies pursued in practice we need first to review the key impediments to restoring floodplains.

\section{Institutional constraints to floodplain restoration}

What are the principal constraints to floodplain restoration? A simple answer would be: those human activities which have contributed to the loss of functional floodplains in the past. These include primarily settlement development, agricultural land use, flood defence and navigation. The continued importance of these activities poses strong arguments against allowing floodplains to flood naturally and ecosystems typical of floodplains to develop unimpeded.

A closer look, however, reveals many additional factors related to the institutional challenges of changing entrenched practices of land and water use which can frustrate schemes to restore floodplains (on institutional constraints, see WWF 2000). Our policy analyses and case studies in France, Germany and England (see Section 7 below) have identified several of these constraints which, individually or in conjunction, prevent flood restoration schemes 
taking place or limit the scope and effectiveness of those implemented. The most important constraints relate to the following:

\section{a) Land use / ownership:}

Owing to their favourable topography floodplains are generally very attractive sites for development. The quality of the soil makes them amongst the most productive land types for agriculture. The biodiversity and landscape value of undeveloped floodplains is also very high. Consequently, changes to land use on floodplains usually confronts a variety of vested interests relating primarily to agriculture/forestry, urban development, recreation, landscape enhancement, biodiversity and flood defence. Land ownership on floodplains, largely because of its historically high value, tends to be particularly fragmented and complex, requiring the support of a large number of landowners and users. In instances where changes to land use on floodplains have substantial effects downstream, the constellation of affected parties can be huge and highly varied.

\section{b) Policy / planning instruments:}

Many of the policy and planning instruments designed to protect floodplains from development are in practice ineffective. Planning regulations to limit urban development on floodplains have in the past generally failed to halt the loss of existing floodplains, let alone encourage their restoration. The financial incentives for farmers or landowners to accept changes to land use, for instance via agri-environment schemes, have achieved only meagre results because they generally provide inadequate long-term financial support to cover the risks involved. Many financial incentives are indeed counter-productive: the emphasis of flood defence funding on building and maintaining defence structures or of the Common Agricultural Policy on increasing agricultural productivity are cases in point. Finally, nature conservation legislation is generally oriented towards protecting existing habitats rather than creating new ones; protected area status on a floodplain can for this reason act as a constraint on restoration.

\section{c) Coordination:}

Floodplain restoration requires multi-dimensional coordination between the diverse actor groups affected, which poses a major challenge of strategic and operational complexity. Difficulties apply to coordination across diverse policy fields and actor groups (problems of horizontal interplay), collaboration across the administrative boundaries of a catchment 
(problems of spatial fit), working with inconsistencies between national and EU policy incentives (problems of vertical interplay) and determining the appropriate scale for each activity (problems of scale).

\section{d) Entrenched practices / mindsets:}

Perhaps the most severe constraint, and certainly the hardest to change, is the everyday practices and mindsets of key stakeholders. Many people are unwilling to change ways of using the land or the river which have been established for generations, whatever the rational arguments in favour of restoration. Farmers continue to want to keep their land free from flooding at all costs, flood defence managers continue to prefer hard engineering solutions for flood protection, nature conservationists continue to seek protection for a favourite species.

Although the intensity and significance of these constraints vary between different national and regional contexts, they are common to all the countries studied. Their combined impact has been to limit the development of floodplain restoration schemes in the past.

\section{Early generation schemes: Keeping restoration simple}

The first schemes to restore floodplains in Europe were, largely for these reasons, limited in size and scope. Up until the late 1990s most floodplain restoration schemes were small-scale and site-based. They were typically single-issue projects, targeting environmental improvements as a rule. They involved only a small number of actors and policy instruments, often relying on a single source of funding for the physical interventions. It is generally true to say that these early generation restoration schemes were conducted largely in isolation from national or regional policy initiatives, whether for flood protection, biodiversity enhancement or rural development. Examples include the Rheinvorland-Süd project in Germany, a scheme to improve hydrological and ecological conditions by widening ducts and removing structures in a section of the Rhine floodplain near Rastatt, the Long Eau project in England, in which flood banks were set back for primarily environmental benefits, and the Bourret project in France, a scheme to reconnect an old arm to the river Garonne and restore an alluvial forest again primarily for environmental benefits. 
Still today, many floodplain restoration schemes belong to this early generation of projects of limited scope and scale. It was, and still is, common for a restoration project to begin as an idea to improve habitat quality along a section of a river of low conservation value. The focus of attention is generally on a single issue, such as fisheries or landscape enhancement. In a typical case, a small group of interested people from the region, many representing government agencies and NGOs engaged in nature conservation, would join together to design and implement a scheme on a particular site. Site selection would be strongly influenced by the willingness of the landowner(s) to cooperate. The area of floodplain restored would generally be small. Instrumental behind the effective implementation, and indeed the existence, of the scheme would often be the ready availability of one or more funding sources to cover the capital costs of conducting the physical interventions (e.g. removing flood banks) and also any loss of revenue incurred by the landowner.

Being relatively unambitious and straightforward, schemes of this kind have tended to avoid the most pressing problems associated with high levels of complexity. They have succeeded in restoring floodplain habitats with limited resources and, in some cases, within a short period of time. With the benefit of relatively straightforward administrative procedures, organisational structures and funding mechanisms they have demonstrated how floodplain ecosystems can be restored on a small scale. The Long Eau scheme in Lincolnshire, England, is a case in point. In less than a year between design and completion two dykes were set back from the river, thereby increasing the standard of flood protection in the surrounding area from a 1-in-10 to a 1-in-30 year flood risk and creating an attractive wet grassland habitat for wintering and migratory birds at a total capital cost of only $£ 70,000$.

These schemes do, however, have several critical limitations. They rarely incorporate a catchment perspective on restoration, but concentrate on the site itself. Being predominantly single-issue schemes, they regularly overlook potential benefits for other policy areas, such as flood protection, recreation or rural development. Little attention is generally paid to cultivating support for the project in the wider policy-making domain, scientific communities or sometimes even in the local community. The performance of many such projects is rarely monitored or evaluated systematically.

In terms of resolving problems of fit, interplay and scale we can observe how schemes of this kind are ill-equipped to meet the principal institutional challenges to floodplain restoration set 
out above. Spatially, the small scale and site focus of the projects offer little opportunity to consider the catchment dimensions of flow regimes and biophysical connectivity beyond the immediate reach. Institutional interplay may be less difficult but only because the number of policy fields and organisations involved is kept small. Integrating the schemes into the development of the locality or region may well prove difficult at a later date for this reason. Problems of scale are reduced to site-based activities, missing valuable opportunities to explore multi-scalar solutions.

\section{Policy shifts and the emergence of new windows of opportunity}

In recent years, shifts in problem awareness and problem-solving approaches in a number of relevant policy fields are creating new openings for restoring floodplains (on the following, Moss et al. 2003). Major flooding events across Europe, growing evidence of climate change, the continued loss and deterioration of valuable habitats, inefficiencies in agricultural production and the cost of maintaining flood defence barriers are prompting growing concern in the public domain across Europe. Local and regional actors are demonstrating growing interest in the potential of functional floodplains to address a variety of localised issues, ranging from flood risks and loss of biodiversity to agricultural restructuring. Policy-makers at national and European levels are critically reappraising many existing institutional regulations and incentives with a view to improving their effectiveness in addressing these pressing issues. The emerging new policies are often not directed at promoting floodplain restoration specifically, indeed they sometimes do not even refer to it as an option. The important point is that, wittingly or unwittingly, they are creating openings which could be used to this end. Collectively, recent policy shifts in a variety of policy fields are opening a 'window of opportunity' for floodplain restoration projects of a more comprehensive and integrated kind.

It is difficult to generalise on policy shifts across Europe but certain trends can be observed in the policy areas of flood protection, water protection, nature conservation, agriculture, forestry, land-use planning and rural development (see Table 1). 
Table 1: Recent policy shifts conducive to floodplain restoration

\begin{tabular}{|l|l|l|}
\hline \multicolumn{1}{|c|}{ Policy field } & \multicolumn{1}{|c|}{ Forces for change } & \multicolumn{1}{c|}{ Policy responses } \\
\hline Flood protection & $\begin{array}{l}\text { Flooding events; climate } \\
\text { change; infrastructure costs; } \\
\text { environmental quality }\end{array}$ & $\begin{array}{l}\text { Flood risk management; soft } \\
\text { engineering techniques; natural } \\
\text { flood storage }\end{array}$ \\
\hline Water protection & $\begin{array}{l}\text { EU Water Framework } \\
\text { Directive; water quality / } \\
\text { quantity problems }\end{array}$ & $\begin{array}{l}\text { Catchment-oriented approaches; } \\
\text { interest in flow regimes, wetlands, } \\
\text { geomorphology }\end{array}$ \\
\hline Nature conservation & $\begin{array}{l}\text { EU Habitats Directive; } \\
\text { concerns for biodiversity }\end{array}$ & $\begin{array}{l}\text { Promotion of functional } \\
\text { floodplain ecosystems }\end{array}$ \\
\hline Land-use planning & $\begin{array}{l}\text { Linkage of flooding events to } \\
\text { land use }\end{array}$ & $\begin{array}{l}\text { Planning mechanisms for } \\
\text { protecting and creating areas for } \\
\text { flood retention }\end{array}$ \\
\hline Agriculture & $\begin{array}{l}\text { Agenda 2000; public health } \\
\text { concerns; environmental } \\
\text { degradation }\end{array}$ & $\begin{array}{l}\text { Improved agri-environmental } \\
\text { schemes }\end{array}$ \\
\hline Rural development & $\begin{array}{l}\text { EU Rural Development } \\
\text { Regulation; spatial disparities }\end{array}$ & $\begin{array}{l}\text { Integrated approaches to rural } \\
\text { economic development }\end{array}$ \\
\hline
\end{tabular}

\section{a) Flood protection}

In response to recent flooding events, concern at climate change and the cost of strengthening physical flood defences, particularly in rural areas, but also in recognition of obligations to protect and enhance the environment, recent changes to flood protection regulations and funding in several countries have created better opportunities for catchment-oriented approaches and soft-engineering techniques of flood protection. The use of functional floodplains for flood storage purposes is gaining credibility in policymaking circles as a consequence. To take an example of a recent policy initiative, Catchment Flood Management Plans (CFMPs), currently being introduced in England and Wales, take a catchment approach to determining areas where flood storage is most suitable. The planned 60-80 CFMPs across England and Wales will provide a general assessment of risks, opportunities and constraints concerning flood management and develop a set of flood-risk management policies for catchments between 1,000 and 5,000 $\mathrm{km}^{2}$. A flood management strategy developed within the framework of a CFMP for the Severn River, for instance, argues the merits of floodplain woodland for habitat 
enhancement and flood mitigation as part of a strategic, catchment-oriented approach to flood management (Environment Agency 2002a).

\section{b) Water protection}

Water protection agencies, concerned at water shortages and motivated by the EU Water Framework Directive (WFD), are showing growing interest in water flow regimes across whole catchments and in the potential of floodplains to improve water quality. The WFD requires surface waters to be restored to a "good status" and advocates river basin management to this end. Implementing the directive will entail paying greater attention than in the past to flow regimes, abstraction levels and the geomorphology of rivers across whole catchments, all factors favourable to floodplain restoration. A guidance document on the role of wetlands in implementing the WFD, a so-called Horizontal Guidance paper, has been produced within the framework of the Common Implementation Strategy process. It includes a programme of measures for better wetland management. The document is, however, not legally binding. Implementation of its recommendations is thus dependent on the discretion of the Member States.

\section{c) Nature conservation}

For nature conservationists restored floodplains represent important habitats which can contribute to meeting biodiversity targets in accordance with the EU Habitats and Birds Directives. The Habitats Directive obliges Member States to restore, as well as to maintain, favourable status to key habitats and species. In the context of implementation many Member States have introduced plans to promote biodiversity that include targets relating to the restoration of wetland habitats. The National Action Plan for Wetlands was introduced in France in 1995 in response to the alarming degradation of wetlands in recent years. In accordance with the plan, 87 wetlands of national importance have been identified by the Ministry for the Environment. Wetlands with this status are subject to environmental monitoring and measures to enhance their ecological quality. The plan has proved a significant driver behind some notable restoration floodplain projects, e.g. La Bassée on the Seine (see below).

\section{d) Land-use planning}

In response to extensive damage caused by recent flooding events, land-use planning regulations are being modified in many countries to offer more effective protection of 
existing floodplains. In some instances they are designating land for the future restoration of functional floodplains. In Germany, for instance, the Federal Regional Planning Act (ROG) of 1998 introduced new categories of planning zones to secure natural areas for flood protection. These designated planning zones, termed "Vorrang- und Vorbehaltsgebiete" under $\S 7$ para.4 ROG, are regarded by some commentators as an important planning initiative towards restoring, rather than simply protecting, floodplains and their habitats. This federal regulation has, for example, created the opportunity for the state of Saxony-Anhalt to identify in its State Development Plan of 1999 a number of flood protection areas behind dykes that could be restored as functional floodplains in the future.

\section{e) Agriculture}

Political pressure is growing for more environmentally-sensitive forms of agriculture and forestry, increasing the funding opportunities for extensive land management practices more suited to functional floodplains. The Agenda 2000 reform of the EU Common Agricultural Policy has given Member States greater powers to attach environmental conditions to the payment of agricultural subsidies that could be used to promote less intensive farming of floodplains. Willingness to consider steps in this direction has been strengthened by growing concern at the consequences of intensive farming practices, in particular for public health, as highlighted by a number of critical incidents in recent years.

\section{f) Rural development}

The EU Rural Development Regulation for 2000-2006 lays the foundations for a more integrated approach to rural development, incorporating agriculture, nature conservation and the diversification of rural economies. Similar thinking at the national level has fostered integrated programmes and projects for rural development that can include floodplain restoration. Land Management Initiatives have been recently introduced in the UK to develop desirable landscapes and agricultural practices with targeted funding programmes. The Severn-Vyrnwy Wetland Land Management Initiative aims to manage water more sustainably in the catchment by taking an integrated approach to the needs of agriculture, conservation and flood defence. In the course of its development it has broadened in scope from a project to create wet grassland as a breeding habitat for wading birds into a collaborative exercise in new ways of managing the rural landscape. 
Spanning these sectoral policy shifts is a general trend towards greater policy integration and stakeholder participation over schemes of this kind, informed in part by debates on sustainable development and new forms of governance.

\section{New generation schemes: Embracing the challenge of complexity}

In response to these recent institutional drivers, but also to a growing recognition of the inadequacies of current ways of managing rivers, a new generation of floodplain restoration schemes is emerging which are of a quite different scope to those of the early to mid-1990s. These schemes deliberately set out to address some of the complex challenges to large-scale, integrated floodplain restoration (on the following, Moss et al. 2003). Distinctive features of the new generation schemes are their multiple objectives, broad spatial scope, long-term orientation, extensive stakeholder involvement, use of instruments from diverse policy fields and linkage to national policy initiatives and policy-making processes:

a) Multiple objectives: Schemes are designed to provide a wide range of benefits affecting several policy areas. Restoring a floodplain can be part of a broader scheme to raise the standard of flood protection, improve groundwater quality, create a more attractive landscape and strengthen rural development.

b) Catchment orientation: From a greater breadth of scope follows a greater breadth of scale since many of the issues addressed demand catchment-oriented solutions. Restoration sites are selected according to their suitability from a catchment - or at least large-scale - perspective and not primarily because they are available.

c) Long-term vision: The long time-frame of many of the issues addressed, such as processes of habitat succession, timber production or the impacts of climate change, prompts a long-term vision for restoration projects extending over several decades.

d) Strong partnerships: Great emphasis is placed on building a broad-based partnership of stakeholders from the relevant policy fields that incorporates NGOs and the local community as well as government agencies. The resulting organisational structures and procedures can be quite complex.

e) Wide consultation: Beyond the involvement of those immediately responsible or affected, the support of a wide range of relevant actors at the regional and national, as well 
as local, level is actively sought. Extensive consultation increases the importance of a process-oriented approach to restoration.

f) Instrument mix: Schemes draw on a wide range of funding, planning and regulatory instruments from the various policy fields addressed. They often seek effective novel combinations, for example between flood defence funding for capital works and agrienvironment payments to cover maintenance costs.

g) Policy linkage: The ambitious objectives and innovative management practices of integrated projects benefit greatly from establishing strong links to policy-making circles. Schemes often act as pilots for new planning or funding initiatives and seek wide publicity for their activities.

In our research (Moss et al., forthcoming) we investigated in detail three examples of this new generation of floodplain restoration schemes: a major dyke relocation project at Lenzen on the river Elbe in Brandenburg, Germany; the Parrett Catchment Project in Somerset, England; and a large-scale flood retention scheme on the Seine upstream of Paris.

The Lenzen project, involving the restoration of ca. 400 ha of floodplain by relocating a dyke on the river Elbe, is one of the largest and most ambitious schemes of its kind in Germany. The project, currently in the early stages of implementation, envisages an elaborate programme of measures for ecological restoration, which includes extensive initial plantings of floodplain woodland. Beyond the restoration and conservation of a floodplain environment, the scheme aims to contribute to improved flood protection at a critical point on the Elbe and to the sustainable economic development of a structurally-weak region, promoting soft tourism, organic agriculture and environmental education. In order to achieve these complex goals, a large array of instruments has been enrolled, including various sources of funding, the designation of protected areas, technical flood protection measures, rural development initiatives, agri-environmental schemes and land consolidation procedures (for further information see http://www.burg-lenzen.de/deichrueckverlegung/welcome.html; Puhlmann and Jährling 2003).

The Parrett Catchment Project in Somerset is a good example of a multi-purpose, catchment-oriented scheme. Launched in 2000, its purpose is to resolve existing conflicts over land and water management activities by building a broad partnership with which to develop innovative forms of sustainable flood management across the whole catchment. A 50-year 
Action Strategy outlines the project's integrated approach to meeting flood defence needs in ways that benefit wildlife, support the local economy and offer new opportunities for rural development. With the support of local and policy communities it has succeeded in accessing substantial funding, stimulating joint projects, initiating a dialogue between actors of the upper and lower catchment, winning national awards and being selected as an example of best practice for flood management (for further information see http://www.somerset.gov.uk/somerset/ete/pcp/; Land Use Consultants 2001; Environment Agency 2002b).

The La Bassée project is designed primarily to minimise the risk of severe flooding of the Paris agglomeration. The planned scheme to create a controlled polder area of some 2,500 ha on the Seine River ca. $70 \mathrm{~km}$ upstream of the city is illustrative of a large-scale, inter-regional solution for better flood protection meeting the needs of a variety of stakeholder groups. The primary attraction of the project is to reduce annual damages from flooding by an estimated $€ 29$ million. Despite the size and institutional complexity of the project local opposition has been minimised by embedding the flood defence measures in a broader programme of regional economic development and biodiversity enhancement, creating the prospect of internal benefits for the affected region. In contrast to most flood defence works in France, there is wide recognition by those involved of the need for a mechanism of inter-regional compensation for the affected region by the downstream beneficiaries (for further information see publications by the Institution Interdépartementale des Barrages Réservoires du Bassin de la Seine, e.g. IIBRBS 2002).

Since these new generation schemes were only launched from the late 1990s onwards and are all at very early stages of implementation it is at present impossible to judge their effectiveness. They would at least appear to have the potential to overcome some of the principal institutional constraints to floodplain restoration which have thwarted or curtailed efforts in the past. Floodplain restoration schemes of this kind are making substantial steps towards addressing problems of fit, interplay and scale. Their catchment orientation and longterm perspective creates better fit between ecosystem properties of the floodplain and the institutional arrangements for its restoration, both in spatial and temporal terms. Building on better interplay between institutions is central to the new generation projects, as is exploiting different scales of action - from national pilots to local management teams - for different purposes. 
However, our research findings caution against over-optimistic expectations from the new generation projects. Early signs suggest that the sheer complexity of the tasks they are tackling and the uncertainties they are exposing are posing a major problem for project management. Building and maintaining the large partnerships takes time and care. Striking an acceptable balance and negotiating trade-offs between diverse policy objectives is very demanding. Accessing multiple funding sources requires a high degree of flexibility to satisfy different funding agencies. Attempts to enrol instruments from different policy fields can reveal serious incompatibilities and inconsistencies. As a result, project design and implementation have become more complex, more time-consuming and more expensive, endangering effective implementation. Efforts to take on problems of fit, interplay and scale are proving in many cases too demanding for project management. This does not query the desirability of addressing these core institutional problems but, rather, raises questions about how project managers can be assisted in doing so.

\section{Rituals of verification: Tightening controls to secure better policy delivery}

Ironically, whilst policy content is generally speaking taking a broader perspective - entailing more comprehensive problem analysis, longer term visions for improvements, better crosssectoral policy integration, more strategic guidance and stronger local partnerships - modes of policy implementation are becoming more restrictive. There is considerable circumstantial evidence from all three countries studied that policy makers are tightening controls over those entrusted with implementation as a means of improving policy delivery. In recent years, a growing array of initiatives have been introduced which set out in detail not only what policy is to be pursued but also how this is to be done at the operational level. Targets are set to measure progress, strict consultation procedures must be followed to gain planning approval, match-funding is required to demonstrate multi-functionality and audits are conducted to assess the performance of projects and programmes alike. These controls are justified by governments in terms of their value in improving accountability, policy integration and, above all, cost-effectiveness. 
Our research suggests, however, that measures of this kind are having important (unintended) negative effects on the ability of project managers to implement floodplain restoration schemes, particularly those of a more comprehensive, integrated kind. The first problem relates to the cumulative effect of the new policy initiatives. Each of the new requirements, whether on policy content or style, may individually make a lot of sense. Experiences of policy implementation reveal, however, that the combined effect of multiple new requirements can be to create a degree of management complexity which can severely delay the progress of some restoration projects and cause others to be shelved. Ironically, therefore, effective policy delivery is being jeopardised by the sheer extent of policy reform.

The second problem is more fundamental, having to do with an emergent culture of control in policy-making circles. The measures to increase accountability, policy integration and costeffectiveness reflect not only very justifiable concerns about effective policy implementation and the efficient use of public funds but also the view of senior management in many government agencies that the policy rethinking described above is not filtering down effectively to the operational level. This argument is used by senior officers to justify tighter control, or "guidance", to assure more effective implementation. Whilst the need for greater strategic guidance over such complex issues as a catchment-scale approach to flood protection is undisputed by all those involved, one of the effects of its implementation has been to restrict the freedom of action of project and programme managers. In the past their judgement, for example on whether to fund a restoration project, was based on their individual expertise, local knowledge and professional experience; today it is framed much more by targets devised at regional, national or even supranational levels. Consequently, the nature of their work is adapting in order to meet what Michael Power has termed the "rituals of verification" required by auditing processes (Power 1997). For the task of restoring floodplains this poses a particular dilemma: whilst recent policy shifts are encouraging floodplain restoration to entertain greater risks and uncertainties, administrative procedures to assure policy implementation are becoming increasingly risk-averse.

In terms of fit, interplay and scale the picture here is more differentiated. Recent policy initiatives relating to floodplain restoration are certainly addressing very clearly problems of spatial and temporal fit, taking a more catchment-oriented and long-term perspective on the river and land management. Inter-sectoral interplay is also strong. Vertical interplay and issues of scale appear more problematic, however. The rhetoric of policy documents tend to 
be very supportive of multi-level and multi-direction governance. The reality, whether intentional or not, is often very different, with control mechanisms of central government agencies reaching down into the operational level of project management to an unprecedented extent. This, it appears, is undermining both project implementation and, ultimately, policy delivery.

\section{Conclusions}

We can conclude that recent shifts in problem awareness and problem-solving approaches are opening windows of opportunity for floodplain restoration. In a number of relevant policy fields, notably flood protection, water protection, nature conservation, land-use planning and rural development, policy initiatives are being taken which, wittingly or unwittingly, are creating institutional frameworks favourable to the restoration of functional floodplains. At the same time there is a growing willingness amongst local and regional actors to restore floodplains as one way of addressing a variety of local issues, ranging from flood risks and loss of biodiversity to agricultural restructuring.

This interest at both the strategic and operational levels has combined in several instances to stimulate the emergence of a new generation of floodplain restoration schemes. These schemes would appear to possess the potential to overcome some of the key deficiencies of small-scale, single-issue schemes of the past by taking a longer-term and catchment perspective on floodplain restoration, building strong partnerships, linking in to policy development and making use of a variety of policy instruments. The very complexity of these new generation schemes is, however, posing serious problems for project management. A floodplain restoration scheme of this kind requires a lot of time, money and support from all the stakeholders, which is not always available. The need to meet so many requirements, consider so many factors and satisfy so many interested parties frequently results in ambitious floodplain restoration schemes being seriously delayed, heavily revised or, in extreme cases, shelved altogether.

Problems of project management are being further aggravated by a lack of sensitivity of policy towards the unintended effects it is having at the operational level. In order to improve the implementation of new policies favourable to floodplain restoration policy makers are 
introducing procedural specifications which require project managers to collaborate widely, seek cross-sectoral synergies and exploit all available opportunities to maximise benefits. These requirements have undoubtedly encouraged greater awareness of policy interconnectivity in general and the emergence of more integrated restoration projects in particular. However, their cumulative impact has been to render more difficult the process of implementing restoration schemes and to limit the scope of project managers to act independently and use their discretion.

In future, more consideration needs to be given to how individual policy incentives work in conjunction with others; that is, how they alter the existing institutional setting. In addition, policy-makers need to be more sensitive to the contexts of action in which their instruments operate. What makes a policy instrument effective is not the assumed preferences of individuals acting according to a rational choice logic but the real scope and willingness of stakeholders to alter their practices. More feedback into policy-making processes is needed about the real-life experiences of project management and stakeholder involvement at the operational level. This will require more monitoring of how and why policy instruments do or do not work in practice. Policy needs to provide not only targets for orientation but also frameworks for developing the necessary economic, social and institutional capital at local and regional level and instruments capable of adapting to the dynamics of a floodplain restoration process. On this basis policy-makers and project managers alike should be better equipped to identify and exploit windows of opportunity for the restoration of floodplains in the future.

\section{Acknowledgements}

This paper was presented in various forms at conferences on flood protection and river restoration in Durham, Paris and Leipzig. The author would like to thank all those who commented on earlier drafts, in particular Francine Hughes, Axel Klaphake, Jochen Monstadt, Keith Richards and Manuela Siener. 


\section{References}

[1] Adams, W. M. and Perrow, M. (1999): Scientific and institutional constraints on the restoration of European floodplains. In: S. Marriott, J. Alexander and R. Hey, eds.: Floodplains: Interdisciplinary Approaches. Geological Society, London. Special Publications, 163 (1999), 89-97

[2] Adams, W. M., Perrow, M. R. and Carpenter, A. (2004): Conservatives and champions: river managers and river restoration discourses in the United Kingdom. Environment and Planning A 36, 1929-1942

[3] Adger, W.N. and Luttrell, C. (2000): Property rights and the utilisation of wetlands. In: Ecological Economics 35 (2000), pp.75-89

[4] Breit, H., Engels, A., Moss, T. and Troja, M., eds. (2003): How Institutions Change. Perspectives on Social Learning in Global and Local Environmental Contexts. Leske + Budrich, Opladen.

[5] Brookes, A. (1996): Floodplain restoration and rehabilitation. In: M.G. Anderson, D.E. Walling and P.D. Bates, eds: Floodplain Processes. John Wiley, Chichester, Sussex, pp.553-576

[6] Environment Agency (2002a): River Severn Strategy. A Flood Management Strategy for the River Severn Corridor. Scoping Report, January 2002

[7] Environment Agency (2002b): The Parrett Catchment. Water Management Strategy Action Plan. Environment Agency, Exeter, Spring 2002

[6] Gren, I.-M., Groth, K.-H. and Sylvén, M. (1995): Economic Values of Danube Floodplains. In: Journal of Environmental Management (1995) 45, pp.333-345

[7] Hodge, I. and McNally, S. (2000): Wetland restoration, collective action and the role of water management institutions. In: Ecological Economics 35, pp.107-118

[8] Hughes, F.M.R., ed. (2003): The flooded forest: guidance for policy makers and river managers in Europe on the restoration of floodplain forests. Department of Geography, University of Cambridge, Cambridge, UK, pp.6-23.

[9] Hughes, F.M.R. and Rood, S.B. (2001): Floodplains. In: A. Warren and J.R. French, eds.: Habitat Conservation: Managing the Physical Environment. John Wiley \& Sons Ltd., Chichester, UK, pp.105-121.

[10] IIBRBS - Institution Interdépartementale des Barrages Réservoires du Bassin de la Seine (2002) : Bilan des connaissances relatives au project hydraulique. IIBRBS, Paris 
[11] Land Use Consultants (2001) : The Parrett Catchment Project. An Action Strategy for Integrated Catchment Management. Manuscript

[12] Moss, T. (2003): Solving Problems of 'Fit' at the Expense of Problems of 'Interplay'? The Spatial Reorganisation of Water Management following the EU Water Framework Directive. In: Breit, H., Engels, A., Moss, T., Troja, M., eds.: How Institutions Change. Perspectives on Social Learning in Global and Local Environmental Contexts. Leske + Budrich, Opladen, pp.85-121

[13] Moss, T., Klaphake, A., Monstadt, J. and Siener, M. (2003): What prospects for restoration? In: F. Hughes, ed.: The Flooded Forest. Guidance for policy makers and river managers in Europe on the restoration of floodplain forests. University of Cambridge, Cambridge, pp.71-84

[14] Moss, T., Klaphake, A. and Monstadt, J., eds. (forthcoming): Restoring Floodplains in Europe: Policy Contexts and Project Experiences. IWA Publishing, London

[15] Petts, G. E. (1996): Sustaining the ecological integrity of large floodplain rivers. In: M.G. Anderson, D.E. Walling and P.D. Bates, eds: Floodplain Processes. John Wiley, Chichester, Sussex, pp.535-551

[16] Power, M. (1997): The Audit Society. Rituals of Verification. OUP, Oxford

[17] Puhlmann, G. and Jährling, K.-H. (2003): Erfahrungen mit "nachhaltigem Auenmanagement" im Biospärenreservat "Flusslandschaft Mittlere Elbe”. In: Natur und Landschaft 4 (2003), pp.143-150

[18] Tunstall, S.M., Tapsell, S.M. and Eden, S. (1999): How Stable are Public Responses to Changing Local Environments: A 'Before' and 'After' Case Study of River Restoration. In: Journal of Environmental Planning and Management 42(4), pp.527547

[19] Turner, R.K., van den Bergh, J.C.J.M., Söderqvist, T., Barendregt, A., van der Straaten, J., Maltby, E. and van Ierland, E.C. (2000): Ecological-economic analysis of wetlands: scientific integration for management and policy. In: Ecological Economics 35 (2000), pp.7-23

[20] Ward, J.V., Tockner, K. \& Schmeier, F. (1999) Biodiversity of floodplain ecosystems: ecotones and connectivity. Regulated Rivers: Research \& Management, 15, 125-139

[21] WWF (2000): Wise Use of Floodplains. Policy and Economic Analysis of Floodplain Restoration in Europe. Opportunities and Obstacles. Report, November 2000

[22] Young, O. (1999): Institutional Dimensions of Global Environmental Change. Science Plan. IHDP Report No.9; Bonn; IHDP 
[23] Young, O. (2002): The Institutional Dimensions of Environmental Change. Fit, Interplay, and Scale. Cambridge (MA); MIT Press

[24] Zöckler, C. (2000): Wise Use of Floodplains - LIFE Environment Project: A Review of 12 WWF River Restoration Projects Across Europe. WWF European Freshwater Programme, Copenhagen 